\title{
STRATEGIES FOR RECYCLING CdTe PHOTOVOLTAIC MODULES
}

\author{
Chris Eberspacher and Charles F. Gay \\ UNISUN, Newbury Park, CA 91320 USA \\ Paul D. Moskowitz \\ Brookhaven National Laboratory, Upton, NY 11973 USA
}

\begin{abstract}
Recycling end-of-life cadmium telluride (CdTe) photovoltaic (PV) modules may enhance the competitive advantage of CdTe PV in the marketplace, but the experiences of industries with comparable Environmental, Health and Safety (EH\&S) challenges suggest that collection and recycling costs can impose significant economic burdens. Customer cooperation and pending changes to U.S. Federal law may improve recycling economics.
\end{abstract}

\section{INTRODUCTION}

PV technology is undergoing a transition, evolving from the traditional crystalline sillicon to a new generation of low-cost thin-films. One of the most promising thin film PV technologies is CdTT. Large-area CdTe modules have been fabricated with efficiencies of ca. $10 \%$, comparable to crystalline silicon modules commercially available today [1]. In full-scale production CoTTe PV is projected to be very competitive in both performance and price. Groups in the United States, Japan and Europe are actively working to commercialize CdTe PV technology.

This paper focuses on issues related to the recycling of end-oftife CdTe PV modules. Recycling is one element of a broader study of the Environmental, Health and Safety (E,H\&S) issues related to CdTe materials and.PV products. The broader study examined issues of public perception and customer preference in the context of analyzing the economics and logistics related to the field use and end-oflife recycling of CdTe PV products. Existing E,H\&S data was reviewed, U.S. Federal laws were analyzed, prospective vendors and customers for CdTe PV were surveyed, and public acceptance and recycling strategies of industries facing comparable E,H\&S issues were evaluated.

Comparatively little E,H\&S data exist for CoTe materials in general and CdTe PV modules in particular. Most existing statutes regulate CdTe based on the better-known hazards of elemental cadmium (Cd) and tellurium (Te). CdTe PV products may face challenges in the marketplace related to customers' apprehensions about CdTe based in a large part on the lack of differentiation between $\mathrm{CdTe}$ and $\mathrm{Cd}+\mathrm{Te}$.
Additional E,H\&S data are needed on CoTTe-based materials, and programs are essential to better educate customers and the public on the nature of these materials.

Everyday comparisons are useful in orienting the customer to the relative risks and benefits of CdTe PV in comparison with other energy sources and other well-accepted products. For example, a prototypical $2 \mathrm{kWp}$ CdTe PV residential array might contain ca. $150 \mathrm{~g} \mathrm{Cd}$, and an average U.S. household might at any given time have eight each size $C$ and size $A A$ rechargeable NiCd batteries, containing in total $60-90 \mathrm{~g} \mathrm{Cd}$. Thus, an average household may already have consumer goods containing amounts of $\mathrm{Cd}$ comparable to the $\mathrm{Cd}$ in a residential CdTe PV array [2]. The relative risks of CdTe modules can be reduced by an effective collection and recycling program aimed at diverting end-of-life CdTe PV modules from uncontrolled landfills, and such a recycling program would likely be more manageable for the ca. $\$ 10,000-20,000$ PV array than for the $\$ 30-60$ battery set.

\section{U.S. LAW}

The key law affecting CdTe PV product use and end-oftife handling in the U.S. is the Resource Conservation and Recovery Act (RCRA). RCRA regulates the disposal of all solid wastes and sets strict guidelines for record keeping, labeling, packaging, transportation, siting, inspections, training, and emergency planning for the generation, transport, storage and disposal of hazardous wastes.

A key differentiation in the complexity of handling a waste material under RCRA is the determination of whether the waste is "hazardous" and must be handled according to strict guidelines, or whether a waste is non-hazardous and can be disposed of simply as common trash. Hazardous wastes are determined either by definition (i.e. "listed" in the RCRA text) or by testing. CoTe is not "listed" as hazardous, so CdTe-containing products are tested using a series of tests, including the Toxicity Characteristic Leaching Procedure (TCLP) test designed to predict risks of groundwater contamination by leaching. In preliminary tests on a very limited sample set, experimental CdTe modules failed the TCLP tests [ø]. More recently, prototype CdTe modules passed the TCLP test [4,5].

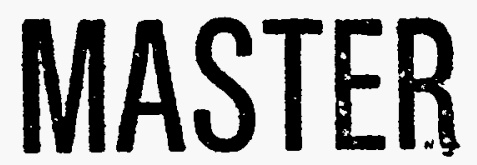

This research was performed under the auspices of the United States Department of Energy under Contract 
If modules "pass" the TCLP, then by U.S. Environmental Protection Agency (EPA) toxicity standards end-of-life modules are non-hazardous trash and require no special handling. This greatly simplifies disposal. Hence passing TCLP is a key to profitability for any commercial product and must be a primary design goal for PV modules. However, passing TCLP does not in itself end consideration of collection and/or recycling programs. State and local laws may impose additional requirements, and long-term business planning may dictate pro-active programs beyond those required by present law. For example, rechargeable NiCd batteries used in U.S. households currently are exempted from being handled as hazardous wastes because RCRA exempts all household wastes. In spite of this exemption and at considerable expense, the $\mathrm{NiCd}$ battery industry has actively encouraged laws facilitating used NiCd battery collection and recycling in order to reduce the migration of $\mathrm{Cd}$ into municipal landfills via used NiCd's and in tum the likelihood that regulations will be promulgated restricting $\mathrm{NiCd}$ use.

Conversely, if modules "fail" TCLP then they are defined under RCRA as a hazardous waste at end-of-ife. This is not necessarily a severe problem for the module manufacturer in that RCRA disposal regulations apply to the generator of the waste, which in most cases will be the module user, not the module manufacturer. However, if CdTe PV module users are faced with high module disposal costs, then CdTe module sales may suffer, so CdTe PV module manufacturers may choose to set up and co-fund the proper disposal of end-of-life modules that fail TCLP. Classification as a hazardous waste significantly increases cisposal costs, whether one chooses disposal in a controlled landfill or reclaim through various means.

Thus, either for public relations, regulatory requirement, or commercial necessity, CdTe module manufacturers and vendors might consider a collection and recycling program for end-of-life CdTe modules.

\section{STRATEGIES OF COMPARABLE INDUSTRIES}

Numerous existing industries face E,H\&S issues comparable to those facing CdTe PV, and the public acceptance and recycling strategies of those industries are useful guideposts for how the CaTe PV industry might proceed.

Since the vast majority $\left(99.5^{+}\right.$wt\%) of an unframed CdTe PV module is glass, CdTe PV modiles might be recycled through existing glass recycling pathways. However, the high cleanliness specifications of sheet glass manufacturers effectively preclude the recycling of CdTe PV modules as part of the sheet glass recycling stream. Container glass has lower cleanliness standards, but the economics of container glass recycling is generally negative, driven primarily by litter reduction and landfill space conservation, and the addition of CdTe into the beverage container glass supply poses complications.

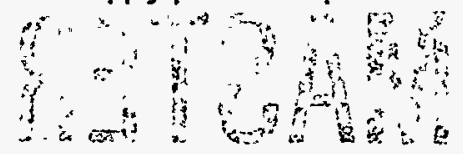

$\mathrm{Pb}$-acid batteries are widely recycled because the reclaim value of the $\mathrm{Pb}$ metal, and to a lessor extent the plastic casings, is sufficient to offset collection and electrolyte treatment costs. Today over $90 \%$ of Pb-acid automotive batteries sold in the U.S. are eventually recycled [6], due largely to laws mandating a "reverse distribution chain" in which battery retailers charge customers a deposit on the sale of new batteries and collect used batteries for recycling. Retailers are in turn paid up to ca. $50 \% / b a t t e r y$ by intermediary collection entities and/or primary recyclers.

End-of-life Pb-acid batteries are defined as "hazardous" under RCRA and would be costly to recycle if not for specific RCRA exclusions intended to encourage battery recycling by easing the costs and complexity of collecting and transporting used $\mathrm{Pb}$-acid batteries. The EPA granted these exclusions in view of the well-established and highlyeffective Pb-acid battery recycling system and in order to further encourage recycling and materials reuse. This suggests an opportunity for the PV industry to mitigate collection and recycling costs by setting up an effective PV module recycling program and seeking regulatory relief to improve the economics of such a program. This also underscores the importance of cooperative collective action by CdTe PV module manufacturers to establish workable pro-active recycling and educational programs.

$\mathrm{NiCd}$ batteries are widely used in rechargeable applications, and sales of NiCd batteries are increasing as sales of portable electrical devices increase. NiCd batteries "fail" the TCLP test and thus are considered "hazardous" under RCRA rules. Manufacturers of large industrial NiCd's ease the disposal burdens for their large commercial customers by providing collection and recycling programs, often at little or no cost to the customer. As a result, upwards of $80 \%$ of industrial NiCd's are currently recycled [7].

The most common technique for recycling NiCd's is pyrometallurgical processing in which the battery casing is broken open, the battery pieces are heated to vaporize the $\mathrm{Cd}$, and the $\mathrm{Ni}$ and $\mathrm{Fe}$ support grids are smelted. The largest U.S. recycler of NiCd's is INMETCO, a secondary metal smelter with a primary interest in smelting scrap for resale as Fe-Ni stainless steel feedstock. Cd is a "tramp" metal that is processed at an economic penalty. The reclaim values of the $\mathrm{Ni}$ and $\mathrm{Fe}$ do not fully offset the overall processing costs, and the battery user is typically charged 30 - $40 \% / \mathrm{b}$ for recycling. European and Asian NiCd recyclers generally complete the material life cycle by recycling Cd for reuse in new NiCd's, but total reclaim value is again typically less than total NiCd processing costs.

The mechanics and economics of industrial NiCd battery recycling reveals two important lessons for potential CdTe PV module recycling. First, at the prevailing prices of $\mathrm{Cd}$ and at the low concentrations of Cd in CdTe PV modules (e.g. ca. 0.05 wt\% versus ca. 15 wt\% in NiCd batteries) it is not economic for NiCd recyclers to recover Cd from CdTe PV modules. Second, in the absence of secondary 


\section{DISCLAIMER}

This report was prepared as an account of work sponsored by an agency of the United States Government. Neither the United States Government nor any agency thereof, nor any of their employees, makes any warranty, express or implied, or assumes any legal liability or responsibility for the accuracy, completeness, or usefulness of any information, apparatus, product, or process disclosed, or represents that its use would not infringe privately owned rights. Reference herein to any specific commercial product, process, or service by trade name, trademark, manufacturer, or otherwise does not necessarily constitute or imply its endorsement, recommendation, or favoring by the United States Government or any agency thereof. The views and opinions of authors expressed herein do not necessarily state or reflect those of the United States Government or any agency thereof. 


\section{DISCLAIMER}

Portions of this document may be illegible electronic image products. Images are produced from the best available original document. 
components of high reclaim value (e.g. $\mathrm{Ni}$ and $\mathrm{Fe}$ in NiCd's), CdTe PV module recycling will be at some cost to the end-offlife module owner.

The majority of NiCd batteries sold in the U.S. are smaller consumer batteries, and the majority of such batteries are not at present recycied. RCRA allows such unregulated disposal by private citizens under its broad exemption for all "household" wastes. The EPA has recognized that large volumes of widely disperse small individual quantity wastes like consumer NiCd batteries account for a disproportionate fraction of the hazardous materials entering the uncontrolled solid waste stream. The EPA calls this "universal waste" and intends to amend RCRA with the Universal Waste Rule (UWR). The UWR is directed at facilitating feasible and effective collection and recycling programs by easing key RCRA requirements. Should the UWR be issued, the NiCd battery industry will incorporate and fund an independent entity to collect and recycle consumer NiCd batteries at no cost to the user [7]. Battery collection will be encouraged by setting up retailer collection programs that provide convenient store drop-off points for the user and compensation payments to the retailer.

The corollaries for the CdTe PV industry are clear. First, public relations and regulatory issues can justify collection and recycling programs even if such programs are not economic on their own. Second, the economics of a PV recycling program in the U.S. would be greatly improved if PV modules were included under the UWR exemptions.

\section{PV INDUSTRY AND CUSTOMER SURVEY}

A survey focusing on commercialization issues collected quantitative data on the knowledge, perceptions, preferences and values of prospective purveyors and users of CdTe PV modules. Survey results show that many module users are concerned about materials content, especially about $\mathrm{Cd}$ content; but that products containing regulated materials (e.g Cd in CdTe) would be purchased if the price and performance were competitive and if the modules are conveniently recycled. Most responders now use products containing regulated materials bècause those products are reliable and cost-effective, and half of the responders indicated that their customers typically do not know or care about the materials content in products.

Most responders indicated that they would voluntarily participate in a module recycling program, and the balance indicated that they and/or their customers would participate if they were compensated for handling costs and/or if their customers received some incentives. Responders indicated that they and/or their customers would be more likely to purchase modules that could be conveniently recycled, but that they would be less likely to purchase modules that by law must be recycled or handled as hazardous waste. For example, responders indicated that a module that is comparable to standard crystalline silicon modules in all respects except that it must by law be recycled or disposed of as hazardous waste will likely command market prices of $5-30 \%$ less than crystalline silicon modules, with recycling being less disadvantageous (i.e. 5 - 15\%) than hazardous waste disposal (i.e. $10-30 \%$ ). The non-U.S. responders gave the strongest answers, predicting that future local laws would require module manufacturers to take back end-of-life modules and that modules requiring recycling or hazardous waste disposal could not be sold unless a large incentive was offered to adequately motivate users to retum end-oflife modules. Although all responders indicated a willingness to participate in module recycling and many indicated that module recycling was a positive influence on their choice of modules, few responders indicated that ease of module recycling would command a higher module selling price.

The survey results underscore the differences between customer segments and the importance of educational and marketing materials being carefully targeted to the different customer groups. For example, module and system vendors were the most concerned about materials content and the most likely to specifically identify Cd content as a primary concem, while utilities were the least likely to cite E,H\&S concems. This suggests that utilities might be good target customers for the market entry of CdTe PV modules in so much as utilities would be technically sophisticated customers with no strong pre-conceived aversions to handling products containing regulated materials.

\section{CdTE PV RECYCLING}

Real-world recycling is a dynamic trade-off between costs and benefits and is a strong function of the details of the recycling program and of the regulatory and market environment in which the program operates.

A near-term route for recycling CdTe PV modules is the existing NiCd battery recyclers. While it is likely that $\mathrm{NiCd}$ recyclers will charge the module user for recycling, the simplicity of using the existing fully-permitted NiCd recycling chain facilitates CdTe PV recycling in the nascent stages of CdTe PV manufacturing and marketing.

An alternative recycling route is primary metals smelters. A prototypical glass/glass module structure with $0.15 \mu \mathrm{m}$ CdS and $2 \mu \mathrm{m}$ CdTe layers has only $0.05 \mathrm{wt} \%$ each $\mathrm{Cd}$ and $\mathrm{Te}$, well below the typical metals concentrations in the $\mathrm{Zn}, \mathrm{Cu}$ and $\mathrm{Pb}$ processing byproducts from which $\mathrm{Cd}$ and $\mathrm{Te}$ are generally recovered. At the low concentrations present in a PV module, processing costs would almost assuredly exceed metals value. Furthermore, though nonferrous smelters purchase silicas as fluxing agents for the smelting process, the low-cost soda lime glass used in most PV modules has less free silica than the raw silica sources typically used, and U.S. smelters often use silicas containing trace amounts of precious metals to improve the economics of the overall smelting operation. Thus, it is likely that primary metals smelters will charge the module user and/or manufacturer for recycling 
Another alternative recycling route is secondary metals smelters and cement kilns. Small specialty smelters are being developed for use in treating hazardous materials and might be useable to process CdTe PV modules. Cement kilns now processing a wide range of hazardous wastes at costs significantly below incineration costs might be used to process end-of-life CdTe modules [8].

Hazardous waste landfill disposal of end-of-life CdTe modules by the user is a likely scenario if CdTe modules fail TCL.P tests. Module manufacturers are not at present required to take any economic or legal responsibility for end-of-life modules, but laws exist in some locales requiring battery manufacturers to accept returned end-of-life batteries, and such laws may expand in scope to include PV modules. If the user is not a private citizen exempted under RCRA's household waste exemptions, the module user is faced with landfill costs, taxes, and future liability. Landfill costs in California average $\$ 400$ per 55 -gallon drum of dry solid hazardous waste. Assuming $8 \%$ efficient glass/giass CdTe modules ground up to better use drum volume, this translates to $\$ 0.14 N \mathrm{~Np}$ disposal costs. Hazardous waste generator taxes are ca. \$200/ton for landfill disposal in California, adding ca. $\$ 0.03 \mathrm{Wp}$. Landfill disposal may incur future liabilities, e.g. clean-up expenses.

Hazardous waste incineration by the user largely eliminates future liability, but incineration incurs higher per drum costs and incurs waste generator various taxes. For example, in California solid hazardous'wastes can be incinerated at a cost of ca. $\$ 600 /$ drum, thus incineration fees alone would be ca. $\$ 0.20 \mathrm{~Np}$.

Hazardous waste collection and recycling, whether by the user, the manufacturer, or some separate recycling entity, incurs various direct and indirect costs. An incentive will likely be necessary to encourage users to return end-of-life modules to centralized collection locations, whether via reverse flow through the retail chain or directly to some specific module collection mechanism. Auto battery collection incentives are $\$ 2-10$ on a ca. $\$ 60$ battery; one could reasonably expect a similar amount for a $30-40 \mathrm{Wp}$ module selling at $\$ 1.50-2 \mathrm{~Np}$. Assuming à $\$ 2 /$ module incentive yields ca. $\$ 0.07 \mathrm{~Np}$ in incentive payments. Assuming a centrally located recycling site, one could reasonably expect $\$ 500 /$ ton, or $\$ 0.08 N \mathrm{~Np}$ in shipping and handling costs for bulk, solid, non-radioactive, non-volatile hazardous waste. Actual module recycling would likely come at some cost to the party disposing of the module. NiCd battery recycling charges range from $\$ 0.20-0.70 \mathrm{Ab}$, and costs would be higher without the $\mathrm{Ni}$ reclaim value. Assuming module recycling charges equal to the lowest present costs for battery recycling, one estimates $\$ 0.20 / \mathrm{b}$, or $\$ 0.07 \mathrm{Mp}$. Summing collection incentives, transport, and recycling costs, an estimate of ca. $\$ 0.22 \mathrm{Mp}$ is obtained.

Non-hazardous waste collection and recycling would benefit from the simplified handling of non-hazardous wastes. An incentive would be required to encourage module users to return end-of-life modules to collection points if the user was not otherwise faced with substantial hazardous waste disposal cost. A $\$ 2 /$ module incentive is plausible. Shipping and handling costs for non-hazardous wastes are much less than for comparable amounts of hazardous wastes, but end-of-life modules would likely be shipped back in small shipments through transport means similar to those used to send out new modules. Assuming typical ground transport, one reasonably estimates $\$ 0.25 / \mathrm{b}$, or $\$ 0.09 \mathrm{~Np}$. If nonhazardous modules could be reclaimed for their glass value at $\$ 5 /$ ton, then one estimates a gain of $\$ 0.01 \mathrm{Wp}$. Summing collection incentives, transport costs, and reciaim value, an estimate of ca. $\$ 0.15 \mathrm{~Np}$ is obtained.

It is important to realize that these cost estimates are based on conservative assumptions about the difficulty of collecting and recycling CdTe modules. If the scenarios accurately reflect the disposal options for end-of-life CdTe modules, then CdTe PV technology faces important challenges. It is possible, however; that the desire of modules users to purchase recyclable products and their willingness to voluntarily participate in recycling programs will provide much more positive economics than the scenarios quantified here.

\section{ACKNOWLEDGMENTS}

This work was funded by Brookhaven National Laboratory under Contract No. 725008.

\section{REFERENCES}

[1] J.M. Woodcock et al., "Thin Film CdTe Photovoltaic Cells", $12^{\text {th }}$ EC PVSEC, 1994, p. 948.

[2] Emst \& Young, "Household Battery Waste Management Study", Report \# P402-92-001, California Integrated Waste Management Board, 1992.

[3] K. Zweibel, "Perspectives and Opportunities in Polycrystalline Thin-Film Photovoltaic Technologies", $23^{\text {rd }}$ IEEE PVSC, 1993, p. 379.

[4] M. H. Patterson et al., "Health, Safety, and Environmental Aspects of the Use of Cadmium Compounds in Thin Film PV Modules", Int. PVSEC-7, 1993, p. 521.

[5] M. H. Patterson et al., "Health, Safety, and Environmental Aspects of the Production and Use of CdTe Thin Film Photovoltaic Modules", $12^{\text {th }}$ EC PVSEC, 1994, p. 951.

[6] Battery Council International brochure, December 1991, and personal communications in 1994.

[7] Personal communication with Portable Rechargeable Battery Association.

[8] I. Kim, Chemical Engineering, April 1994, p. 41. 